\title{
A longitudinal study of angular artery island flap, used for reconstruction of facial defects
}

KEYWORDS: mid and upper facial defect, angular artery island flap, ipsilateral or contralateral, local flap, donor area

\section{Introduction}

Considering cosmetic and functional outcome, reconstruction of moderate to large mid $\&$ upper facial soft-tissue defects due to trauma, neoplasm, or infection remains a challenge. We used either ipsilateral or contralateral angular artery island flap in patients with full-thickness soft-tissue defects in those areas.

We present our experience in 30 patients (17 females \& 13 males) with mean age of 65 , with complex soft-tissue defects in mid \& upper face reconstructed with angular artery island flaps.
Defect sizes changed from $1 \times 2 \mathrm{~cm}$ to $3.5 \times 5 \mathrm{~cm}$.

Flap size varied from a length of 2.2 to $6 \mathrm{~cm}$ average (average $4 \mathrm{~cm}$ ) and width of 2.7 to 6.5 $\mathrm{cm}$ (average $5 \mathrm{~cm}$ ). All donor sites were closed primarily. Twenty seven flaps (90\%) healed without any necrosis and completely survived.

Ipsilateral or contralateral angular artery island flap is a very convenient, safe and reliable flap for reconstruction of moderate to large mid and upper facial defects. Good aesthetic outcome for variety of facial defects could be obtained with this flap. Donor site morbidity also less.

\begin{tabular}{|c|c|}
\hline \multicolumn{2}{|c|}{ Table 1. Age distribution. } \\
\hline Age range (years) & Number \\
\hline $31-40$ & 1 \\
\hline $41-50$ & 2 \\
\hline $51-60$ & 6 \\
\hline $61-70$ & 9 \\
\hline $71-80$ & 9 \\
\hline$>80$ & 3 \\
\hline
\end{tabular}

Arghya Bera*, Goutam Guha

RGKAR Medical College Kolkata, West Bengal India

*Author for correspondence: drarghyabera7@gmail.com

\begin{tabular}{|c|c|}
\hline \multicolumn{2}{|c|}{ Table 2. Sex distribution } \\
\hline Sex & Number \\
\hline Male & 13 \\
\hline Female & 17 \\
\hline
\end{tabular}

\section{Table 3. Diabetes.}

Diabetes

Yes

No

\section{Number}

21
Table 4. Nature of lesion.

\begin{tabular}{|c|c|}
\hline Lesion & Number \\
\hline BCC & 18 \\
\hline SCC & 12 \\
\hline
\end{tabular}




\begin{tabular}{|c|c|}
\hline & Table 5. Site of lesions. \\
\hline Site & Number \\
\hline Paranasal & 1 \\
\hline Infra orbital & 6 \\
\hline Medial canthus & 8 \\
\hline Malar region & 6 \\
\hline Nasal dorsum & 4 \\
\hline Nasal tip & 2 \\
\hline Glabella & 1 \\
\hline Nasal ala & 2 \\
\hline
\end{tabular}

\begin{tabular}{|c|c|c|c|}
\hline \multicolumn{5}{|c|}{ Table 6. Size of lesions. } \\
\hline \multicolumn{2}{|c|}{ Length $(\mathbf{c m})$} & & \multicolumn{2}{c|}{ Breadth $(\mathbf{c m})$} \\
\hline Minimum & Maximum & Minimum & Maximum \\
\hline 1 & 4.5 & 1.5 & 5 \\
\hline
\end{tabular}

\begin{tabular}{|c|c|c|c|}
\hline \multicolumn{5}{|c|}{ Table 7. Size of defects. } \\
\hline \multicolumn{2}{|c|}{ Length $(\mathbf{c m})$} & & \multicolumn{2}{c|}{ Breadth $(\mathbf{c m})$} \\
\hline Minimum & Maximum & Minimum & Maximum \\
\hline 2 & 5.5 & 2 & 6 \\
\hline
\end{tabular}

\begin{tabular}{|c|c|c|c|}
\hline \multicolumn{5}{|c|}{ Table 8. Size of flaps. } \\
\hline \multicolumn{2}{|c|}{ Length $(\mathbf{c m})$} & & \multicolumn{2}{c|}{ Breadth $(\mathbf{c m})$} \\
\hline Minimum & Maximum & Minimum & Maximum \\
\hline 2.2 & 6 & 2.7 & 6.5 \\
\hline
\end{tabular}

Table 9. Operative time-time required to create defect, raise flap $\&$ inset of flap. Maximum (mins)

120

\section{Minimum (mins)}

70

Mean

89.17

\begin{tabular}{|c|c|c|}
\hline \multicolumn{3}{|c|}{ Table 10. Post-operative hospital stay. } \\
\hline Maximum (days) & Minimum (days) & Mean \\
\hline 27 & 6 & 12.50 \\
\hline
\end{tabular}

\begin{tabular}{|c|c|}
\hline \multicolumn{2}{|c|}{ Table 11. Complication. } \\
\hline Complication & Number \\
\hline No complication & 23 \\
\hline Partial necrosis & 3 \\
\hline Bulky & 2 \\
\hline Haematoma & 1 \\
\hline Ectropion & 1 \\
\hline
\end{tabular}

\begin{tabular}{|c|c|c|c|}
\hline \multicolumn{5}{|c|}{ Table12. Relation between flap survival and smoking. } \\
\hline Smoking & Complication & No complication & p value \\
\hline Yes & 3 & 8 & 0.698 \\
\hline No & 4 & 15 & \\
\hline
\end{tabular}

\begin{tabular}{|c|c|c|c|}
\hline \multicolumn{5}{|c|}{ Table13. Relation between flap survival and Diabetes. } \\
\hline Diabetes & Complication & No complication & p value \\
Yes & 3 & 6 & 0.397 \\
\hline No & 4 & 17 & \\
\hline
\end{tabular}


A longitudinal study of angular artery island flap, used for reconstruction of facial defects

\begin{tabular}{|c|c|c|}
\hline \multicolumn{3}{|c|}{ Table15. Facial aesthetics. } \\
\hline Best outcome & Worst outcome & Mean outcome \\
\hline 6 & 14 & 8.6 \\
\hline
\end{tabular}

\begin{tabular}{|c|c|c|c|}
\hline Null Hypothesis & Test & Sig. & Decision \\
\hline $\begin{array}{l}\text { The distribution of Flap_L is } \\
\text { the same across categories } \\
\text { of Complication_New. }\end{array}$ & $\begin{array}{l}\text { Independent-Samples } \\
\text { Mann-Whitney U Test }\end{array}$ & $0.054^{1}$ & Retain the null hypothesis. \\
\hline $\begin{array}{l}\text { The distribution of Flap_B is } \\
\text { the same across categories } \\
\text { of Complication_New. }\end{array}$ & $\begin{array}{l}\text { Independent-Samples } \\
\text { Mann-Whitney U Test }\end{array}$ & $0.027^{1}$ & Retain the null hypothesis. \\
\hline \multicolumn{4}{|c|}{$\begin{array}{l}\text { Asymptotic significances are displayed. The significance level is } 0.05 \text {. } \\
\text { 'Exact significance is displayed for this test. }\end{array}$} \\
\hline
\end{tabular}

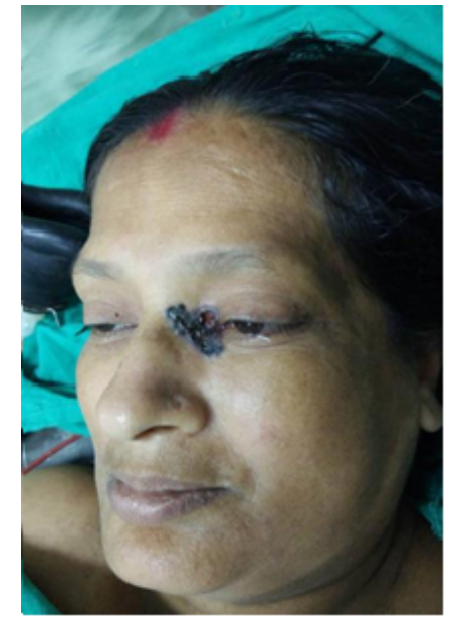

Figure 1: BCC Left medial canthus.

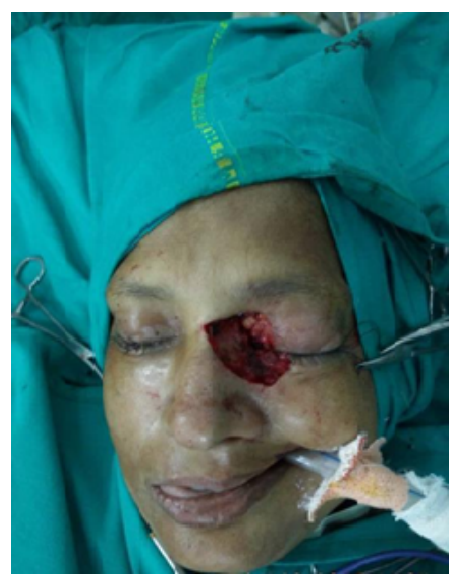

Figure 2: Defect following resection of the lesion.

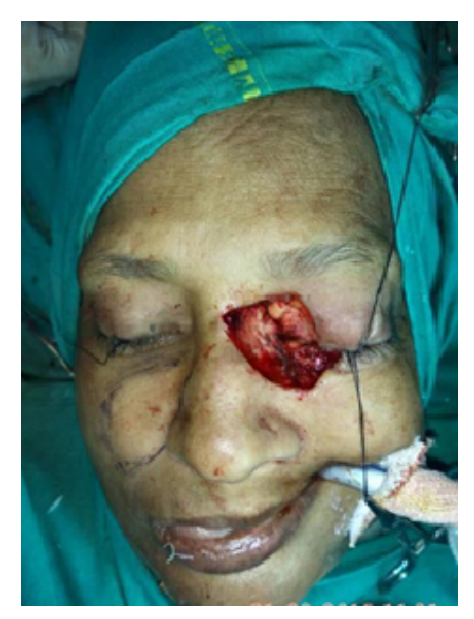

Figure 3: Marking of flap.

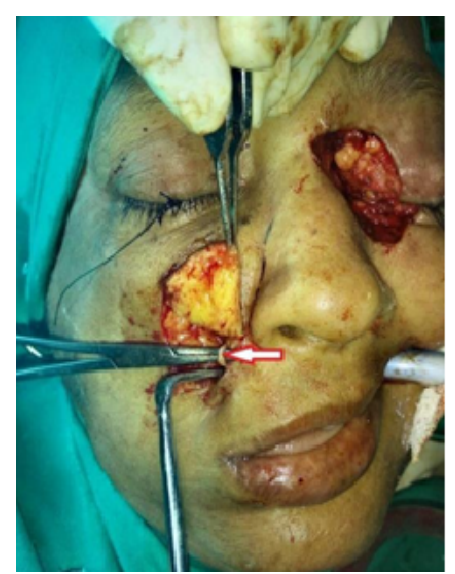

Figure 4: Identification of angular artery red arrow shows angular artery. 


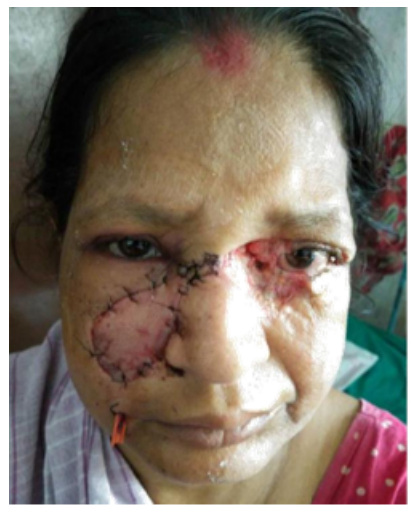

Figure 5: Delay of flap.

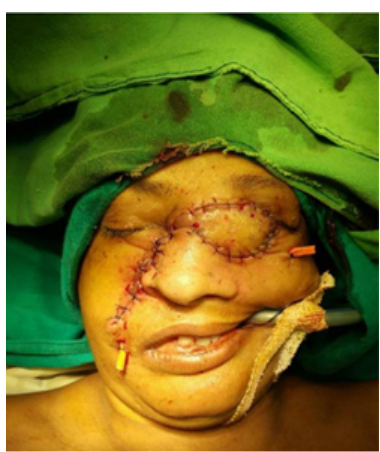

Figure 6: Insetting of flap.

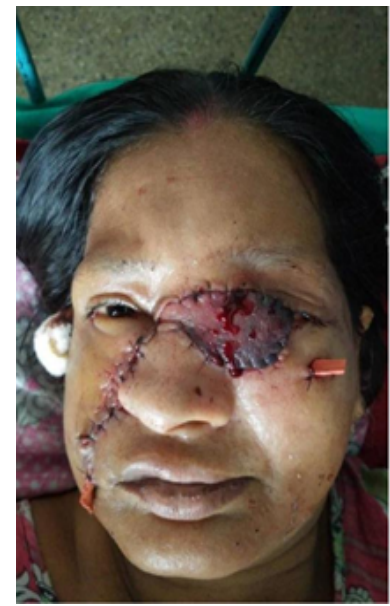

Figure 7: Congestion of the flap.

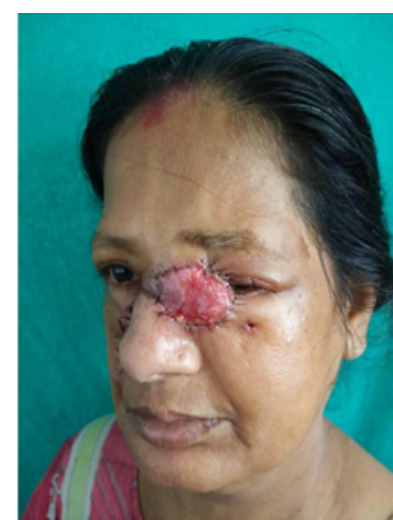

Figure 8: 1 week follow up.

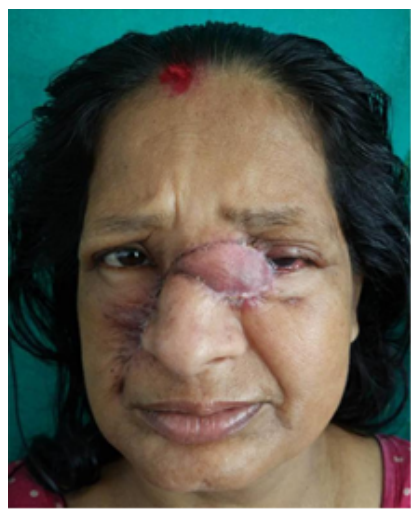

Figure 9: 2 weeks follow up.

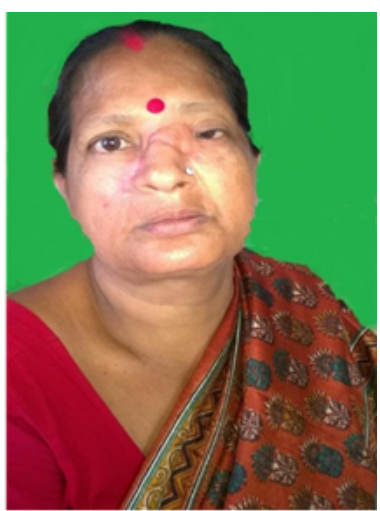

Figure 10: 3 months follow up.

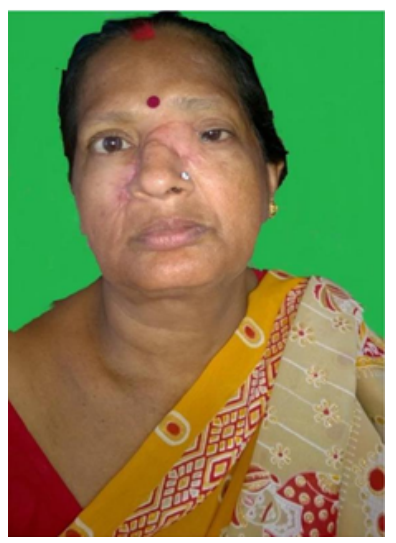

Figure 11: 6 months follow up.

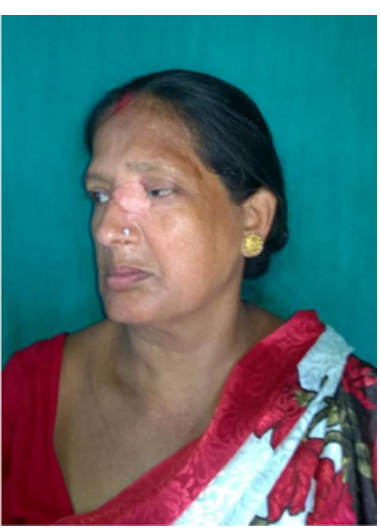

Figure 12: 6 months follow up. 


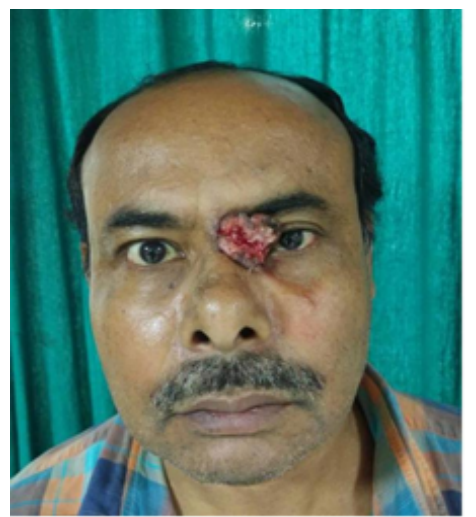

Figure 13: BCC of Left medial canthus \& upper eyelid.

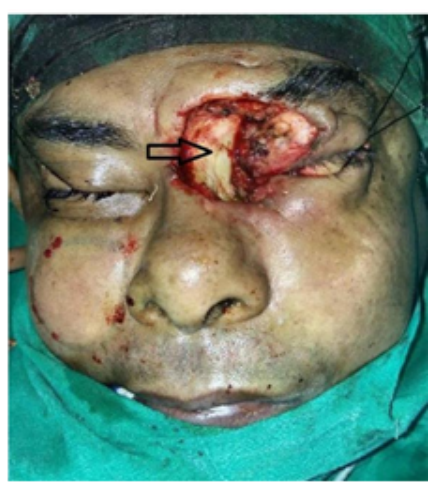

Figure 14: Defect after excision with flap marking arrow showing exposed bone.

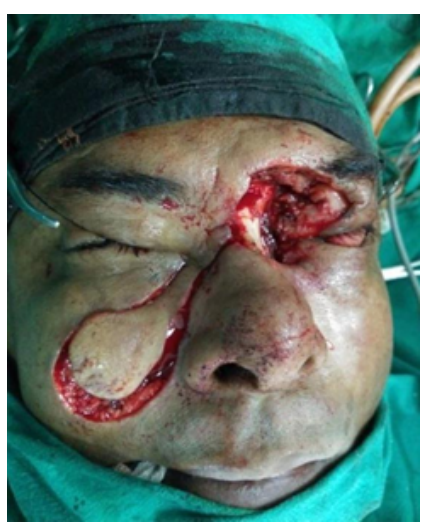

Figure 15: Flap elevation.

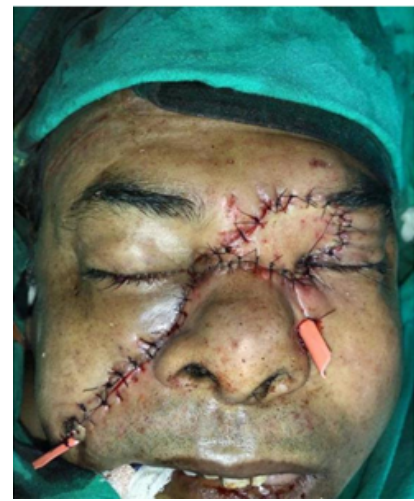

Figure 16: Flap insetting.

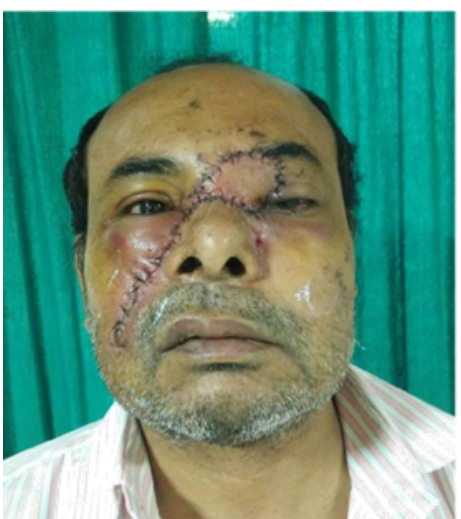

Figure 17: Follow up 2 week.

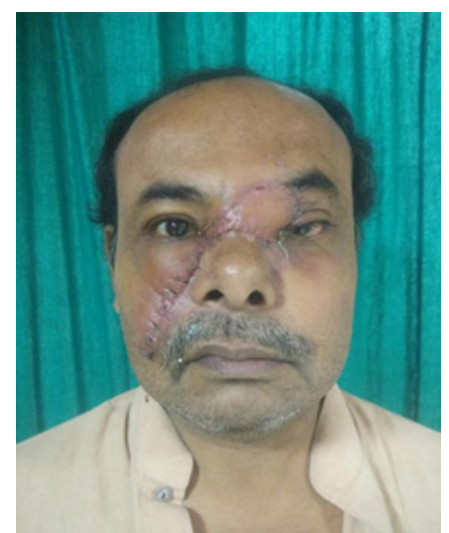

Figure 18: 4 weeks follow up.

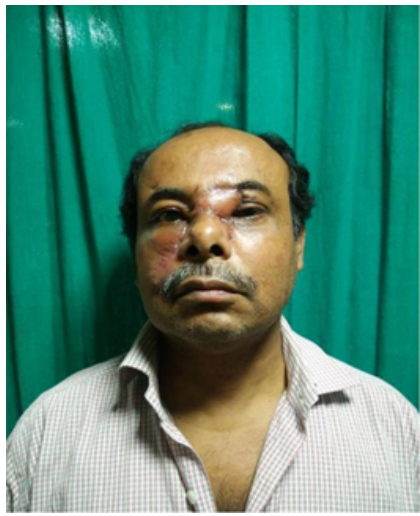

Figure 19: 3 months follow up.

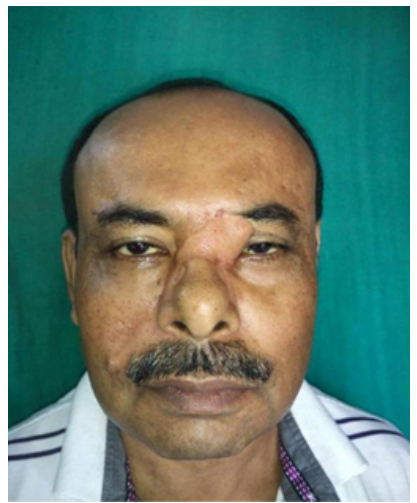

Figure 20: 6 months follow up. 


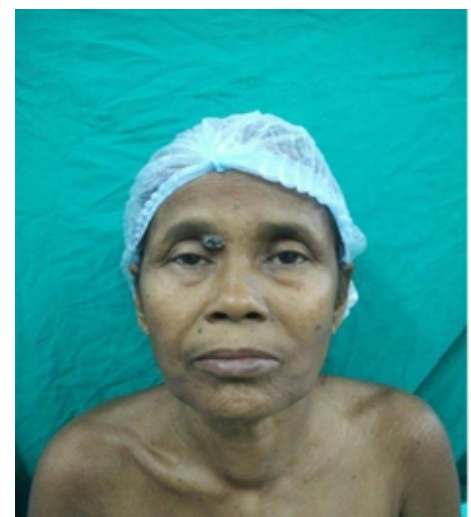

Figure 21: BBCC near Right medial canthus.

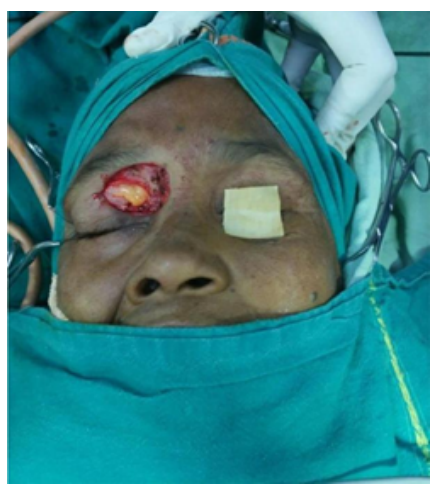

Figure 22: Excision of the lesion.

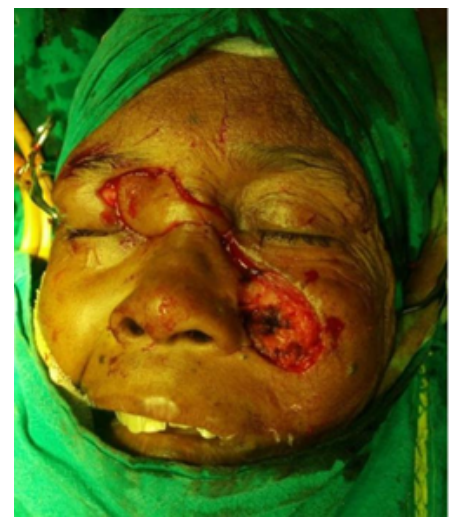

Figure 23: Elevation of flap.

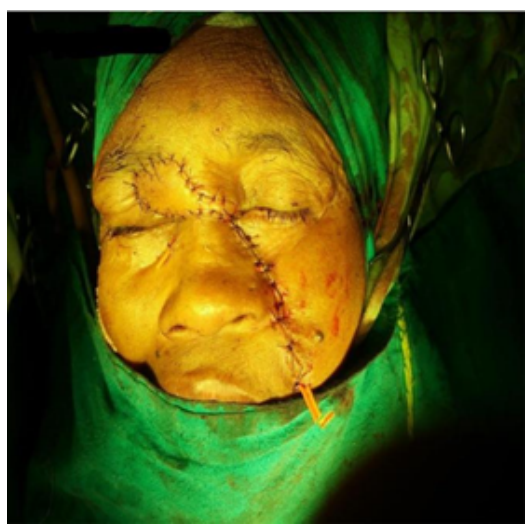

Figure 24: Insetting of flap.

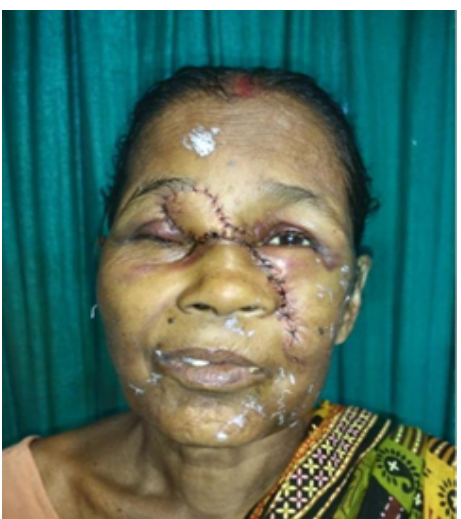

Figure 25: Follow up of 2 weeks.

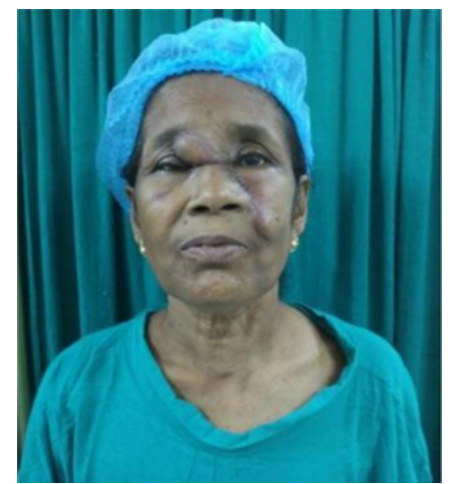

Figure 26: 4 Weeks follow up.

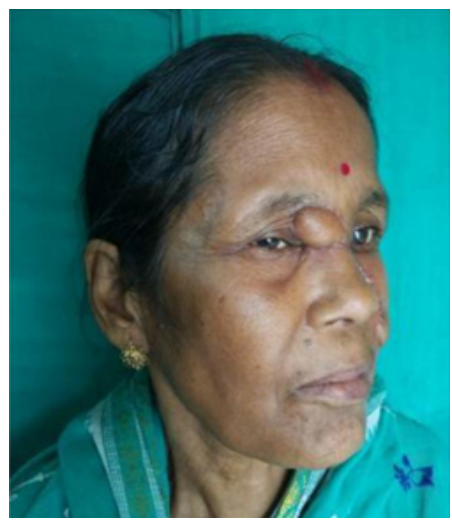

Figure 27: 3 months follow up.

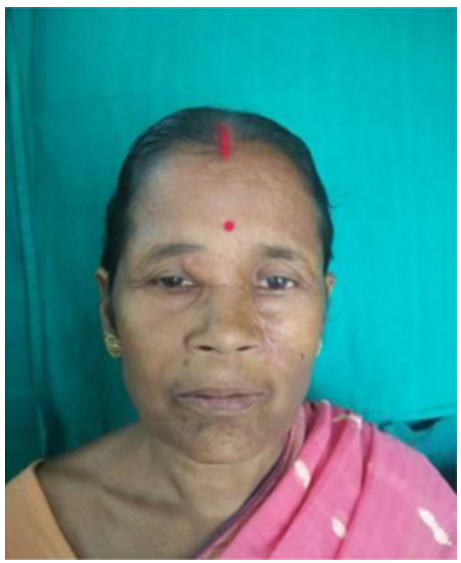

Figure 28: 6 months follow up. 


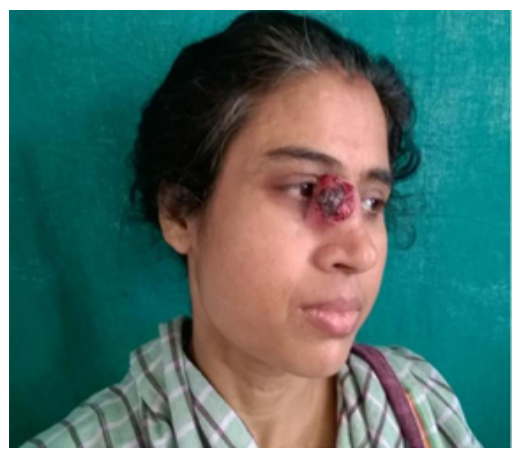

Figure 29: SCC Right medial canthus \& adjacent lateral nasal wall.

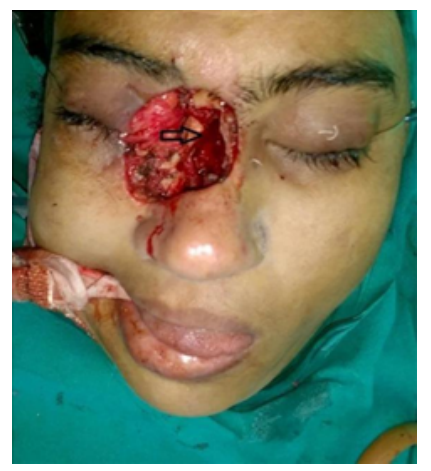

Figure 30: Excision of lesion with nasal bone removal arrow shows removed bone.

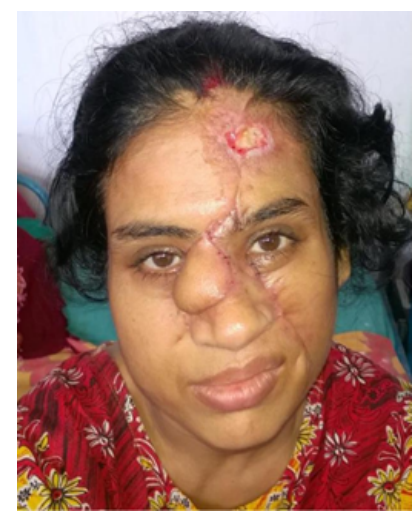

Figure 31: 4 weeks follow up.

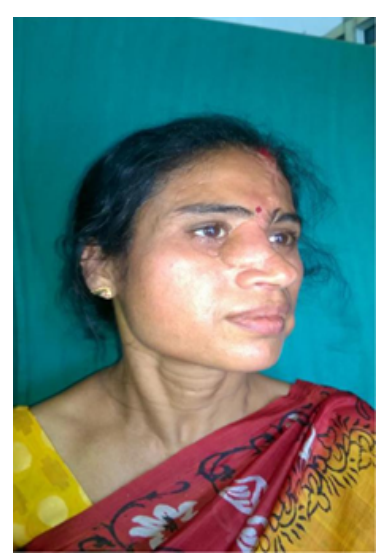

Figure 32: 6 months follow up.

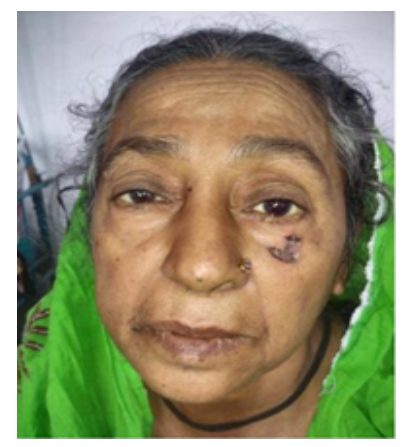

Figure 33: BCC Left infraorbital region.

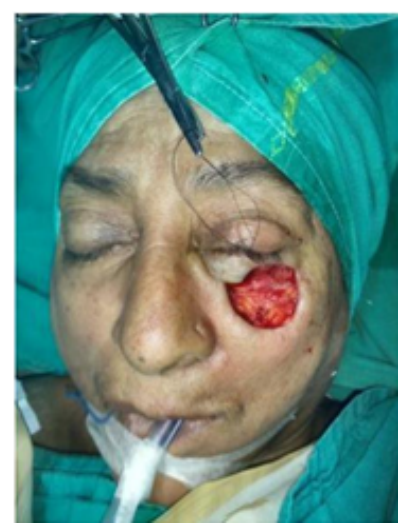

Figure 34: Defect after excision.

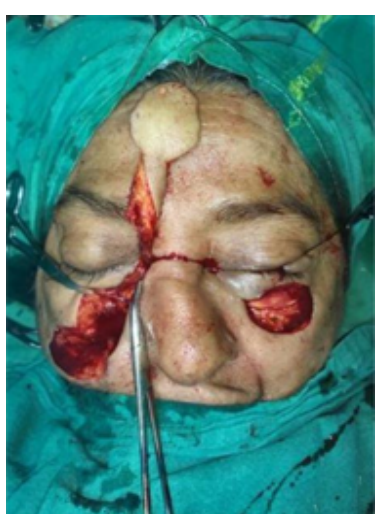

Figure 35: Shows reach of flap over forehead.

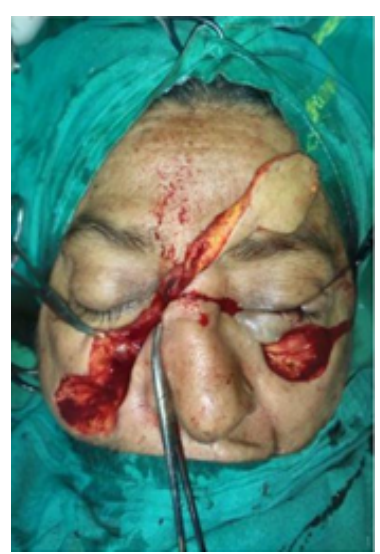

Figure 36: Shows reach of flap over forehead. 


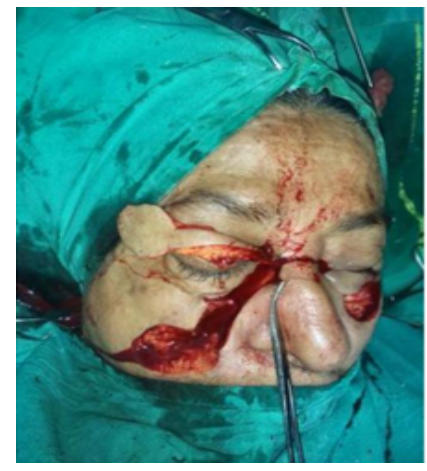

Figure 37: Reach go upto ipsilateral lateral canthus.

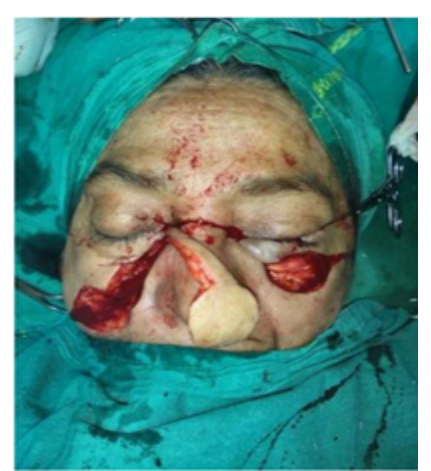

Figure 38: Shows reach of flap to nasal tip.

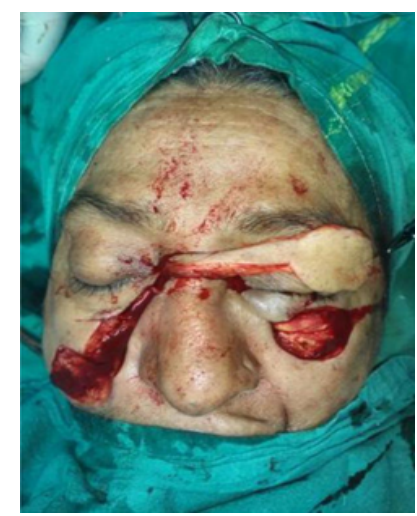

Figure 39: Reach of angular island flap contralateral upper eyelid.

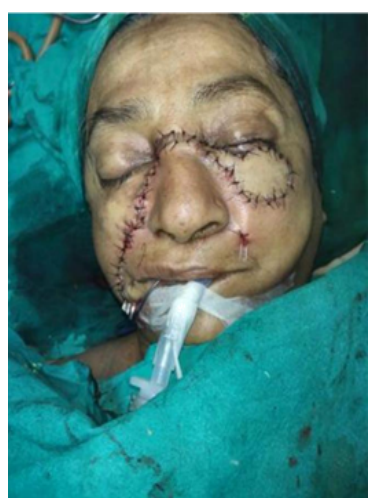

Figure 40: Insetting of flap.

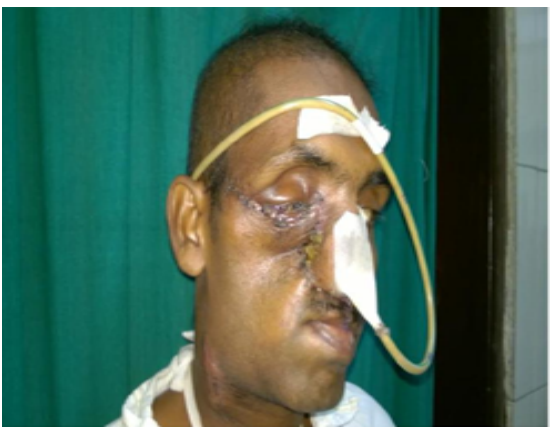

Figure 41: After maxillectomy defect covered with angular artery island flap.

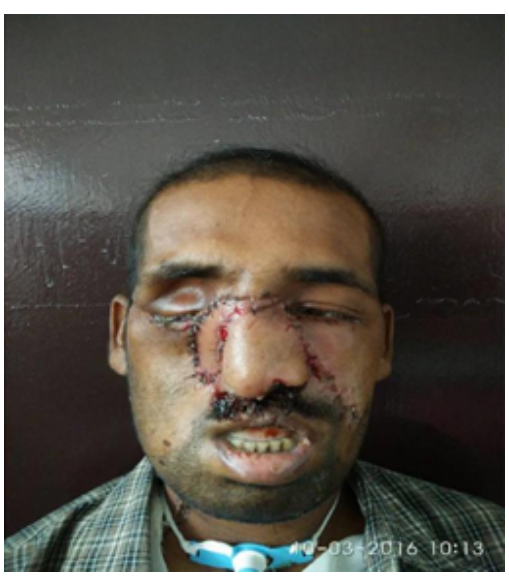

Figure 42: After maxillectomy defect covered with angular artery island flap. 